\title{
DAYA DUKUNG BAHAN BAKU INDUSTRI DAN UMKM BERBASIS POTENSI STOK PADA WILAYAH PENGELOLAAN PERIKANAN
}

\author{
Yonvitner $^{1,2 \star}$, Mennofatria Boer ${ }^{1}$, Rahmat Kurnia $^{1}$ \\ ${ }^{1}$ Departemen Manajemen Sumberdaya Perairan, Fakultas Perikanan dan Ilmu Kelautan IPB. Jalan Agathis \\ No 1 Kampus FPIK-IPB Dramaga, Bogor 16680, Telp 02518622932 \\ ${ }^{2}$ Pusat Studi Bencana LPPM IPB Kampus IPB Baranang Siang, Jalan Raya Padjajaran No 1 Bogor \\ ${ }^{\star}$ Korespondensi: yonvitr@yahoo.com \\ Diterima: 6 Juni 2020/Disetujui: 13 Juli 2020
}

Cara sitasi: Yonvitner, Boer M, Kurnia R. 2020. Daya dukung bahan baku industri dan UMKM berbasis potensi stok pada wilayah pengelolaan perikanan. Jurnal Pengolahan Hasil Perikanan Indonesia. 23(2): 248260.

\begin{abstract}
Abstrak
Kebijakan pemerintah dalam pengelolaan perikanan berbasis Wilayah Pengelolaan Perikanan (WPP) termasuk pada pengolahan yang menyangkut bahan baku. Potensi stok ikan lestari (maximum sustainable yield) merupakan potensi yang siap produksi sebagai konsumsi dan bahan baku olahan industri pengolahan. Penelitian ini bertujuan untuk menentukan besaran stok yang tersedia di setiap WPP sebagai indikator daya dukung bahan baku untuk industri perikanan. Penelitian yang dilaksanakan tahun 2016 ini menggunakan data series 2010-2015 untuk pendugaan kapasitas bahan baku UMKM, dan data 2015-2016 untuk data kapasitas kebutuhan industri. Analisis mencakup ketersediaan bahan baku (stok pada MSY), kebutuhan bahan baku, dan daya dukung terhadap industri secara berkelanjutan dalam setahun. Daerah dengan potensi bahan baku tertinggi adalah WPP 718 yang mampu menopang lebih dari 600 UMKM, dan Industri. Rasio kebutuhan bahan baku industri 34,85\% dan UMKM 65,15\% dengan total bahan baku 5,05 juta ton. Potensi stok pada MSY sebesar 80\% dari stok mampu mendukung 80 industri dan 3031 unit UMKM (total 3111 unit) usaha pengolahan ikan. Jumlah ini lebih rendah dari kondisi saat ini, dimana ada 650 lebih unit Industri, 6350 lebih unit UMKM. Artinya jumlah bahan baku yang tersedia tidak mencukupi untuk mendukung industri yang ada. Untuk menjamin tersedianya stok pada tiap WPP ke depan perlu perencanaan yang lebih baik. Strategi yang dapat dipilih adalah melakukan rasionalisasi industri, bukan impor ikan atau memperkuat sumber bahan baku dari budi daya ikan laut dan air tawar.
\end{abstract}

Kata kunci: Bahan Baku, Daya Dukung, MSY (Hasil Tangkap Maksimum Lestari), Strategi Pengelolaan, WPP

\section{Stock Capacity in MSY at FMA (MSY $\left.{ }_{W P P I}\right)$ for Fisheries Industry on Implementation of Fisheries Management Based on FMA}

\begin{abstract}
Government policy in the fisheries management based on Fisheries Management Area (FMA) includes processing that involves raw materials supply for Micro, Small, and Medium Enterprises (MSME) and Industry. The potential of sustainable fish stocks (maximum sustainable yield) is the potential stock to production and for consumption and processed industrial raw materials. The research aimed to determine the availablity stock at each FMA as an indicator of the carrying capacity of raw materials for the fishing industry. The research conducted in 2016 based on data 2010-2015 for estimating the capacity of MSME raw materials, and data 2015-2016 for industry. The data analysis are avaliability stock in MSY level, total stock for raw material to support for industry and MSME. This research found that from FMA areas with the highest raw material potential was in FMA 718 that were potential to support more than 600 MSMEs and industry to sustain. The allocation material for industry about $34.85 \%$ and $65.15 \%$ for MSMEs from total of 5.05 million tons of raw materials used. So, with the potential stock in MSY (80\%) of the stockcould support 80 industries and 3031 MSME units (3.112 total units) of fish processing businesses. This number was lower than the current condition, where about 650 industrial units and more than 6350 unit of MSME. The amount of raw material available was less than enough to support the existing industry. To sustaining the stock supply in each WPP, strategic plan should be prepared. The rational strategy was by maintenance industrial supply, not by increasing import or enhance the marine and freshwater fish farming.
\end{abstract}

Keywords: Carrying Capacity, FMA, MSY (maximum sustainable yield), Management Strategy, Raw Material. 


\section{PENDAHULUAN}

Pembangunan perikanan yang berkelanjutan (sustainable fisheries) adalah rangkaian aktivitas perikanan yang saling terkait dan menyangkut aspek stok, produksi, logistik, industri, ekonomi, dan kelestarian ekosistem lainya (Pauly et al. 2002). Salah satu target utama kelestarian perikanan adalah keberlangsungan hidup pelaku usaha perikanan termasuk industri pengolahan dan bisnis perikanan skala besar dan kecil. Jadi keberlanjutan perikanan juga menentukan keberlanjutan sosial, ekonomi dan lingkungan (Barclay 2012).

Sejak 20 tahun terakhir industri perikanan berjalan di tempat (bussines as ussual) dengan kontribusi berkisar pada 4 miliar dolar AS (KKP 2018). Industri dibangun tanpa memperhatikan keterkaitan faktor produksi atau stok di perairan, sehingga terjadi defisit stok. Namun potensi tetap diasumsikan tinggi sehingga menimbulkan ketidakseimbangan bahan baku industri. Kepastian ketersediaan bahan baku harus diukur mulai dari wilayah produksi sampai output (produk). Dalam penangkapan, ketersediaan stok disajikan pada satuan wilayah pengelolaan perikanan (WPP N RI).

Kesediaan stok pada satuan WPP, maka bahan baku seharusnya juga diukur dari tingkat WPP. Berdasarkan perpres 18 tentang RPJM 2020-2024 dijelaskan bahwa pembangunan perikanan harus berbasis WPP. Dengan demikian pengukuran kemampuan stok pada setiap WPP perlu ditetapkan secara tepat untuk memastikan daya dukung sebagai bahan baku industri perikanan pada kondisi stok lestari serta untuk memperkuat pengawasan (Krisnafi et al. 2017).

Jumlah stok pada kondisi maximum sustainable yield (MSY) adalah ukuran dari ketersediaan bahan baku yang dapat dimanfaatkan dan juga ukuran untuk menentukan kemampuan resilience (pulihnya) stok setelah eksploitasi (Martel et al. 2013). Untuk itu potensi stok pada MSY di setiap WPP adalah ukuran ketersediaan bahan baku maksimum untuk kebutuhan industri pengolahan ikan dan UMKM. Usaha mikro kecil dan menengah (UMKM) memerlukan bahan baku dalam jumlah yang besar
(Anggraeni et al. 2019; Amin et al. 2018). Sejak 2011-2017 tercatat jumlah UMKM terus meningkat $(2011=58.505$ unit; $2012=58.505$ unit; 2013 $=62.004$ unit; $2014=63.000$ unit; $2015=61.603$ unit; $2016=60.883$ unit dan $2017=60.425$ unit) atau rata-rata masa itu 60.703 unit (Ditjen PDS 2015). Karena ketersediaan bahan baku menjadi urat nadi keberlangsungaan industri pengolahan ikan (Yonvitner 2014). Untuk itu penting dipastikan jumlah bahan baku yang tersedia baik dari penangkapan maupun budi daya.

Karakteristik WPP yang berbeda-beda memberikan perbedaan dari stok ikan dan ekosistemnya. Untuk itu sebagai langkah awal diperlukan informasi jumlah stok dan pemetaan status stok untuk mendukung usaha pengolahan dari sumber daya ikan yang ada di wilayah tersebut. Dalam jangka panjang, upaya ini diperlukan untuk menyiapkan skema investasi secara keberlanjutan secara ekonomi dan kesejahteraan (Suman et al. 2017) pelaku perikanan.

Penelitian inibertujuan untuk menentukan besaran stok yang tersedia di setiap WPP sebagai patokan daya dukung bahan baku industri dan UMKM pengolahan perikanan. Penelitian ini sebagai langkah awal untuk menyiapkan sebuah tata kelola WPP bagi pendukung ekonomi perikanan dan kelautan melalui industri pengolahan ikan.

\section{BAHAN DAN METODE Lokasi dan Waktu}

Penelitian dilakukan secara bertahap, mulai proses pengumpulan dan analisis data. Pengumpulan data bahan baku Industri dilakukan di 6 Provinsi yaitu di Sulawesi Selatan (Makassar), Bali (Denpasar, Denpasar Selatan, Negara, Jembrana), Sulawesi Tengah (Luwuk Banggai), Lampung (Tulang Bawang, Lampung Selatan, Bandar Lampung, Natar), Jawa Tengah (Semarang dan Pekalongan) dan Jakarta. Sedangkan data bahan baku UPIUMKM dikumpulkan pada 11 Provinsi dengan 23 Kabupaten Kota. Jakarta (Jakarta Utara), Jawa Barat (Bogor, Karawang, Indramayu, Cirebon), Jawa Tengah (Pati, Rembang, dan Kendal), Jawa Timur (Gresik, Lamongan, Tuban). Pulau Sumatra di Provinsi Sumatra Selatan (Palembang, Banyuasin), Jambi (Kota 


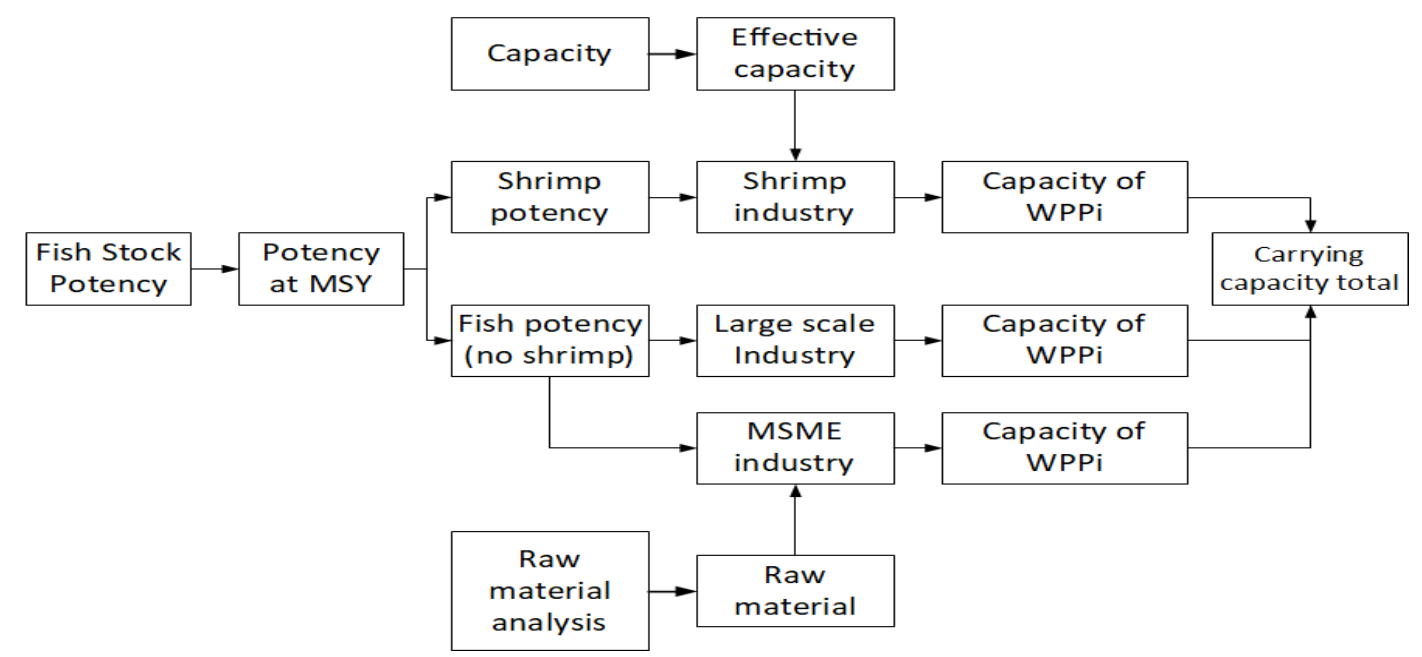

Figure 1 Flowchart of analyzing potential stock at MSY for determining raw materials as an indicator of stock capability of each WPP in supporting fish processing industries or MSMEs

Jambi dan Tanjung Jabung Barat), Kepulauan Riau (Batam dan Tanjung Pinang). Wilayah Sulawesi (Makassar), Maluku Utara (Ternate dan Tidore), Bali (Kota Denpasar, Gianyar) dan Nusa Tenggara Timur (Kupang). Waktu pengumpulan data bahan baku UPI-UMKM 2010-2015, sedangkan data bahan baku industri dikumpulkan pada tahun 2015-2016 .

\section{Analisis Data}

Proses analisis data dilakukan mulai dari analisis bahan baku, analisis potensi stok lestari (MSY) pada permen KP No 50 Tahun 2017, analisis kelompok industri, kapasitas efektivitas industri, dan bahan baku UMKM. Berdasarkan data potensi stok, dengan asumsi bahwa bahan kapasitas efektif dan bahan baku terpasang adalah kebutuhan per unit, maka analisis daya dukung per unit WPP dapat dilakukan. Proses aliran analisis daya dukung disajikan pada Figure 1.

\section{Kebutuhan Bahan Baku}

Formula penentuan kebutuhan bahan baku per tahun berbasis jumlah unit dari UPI. Variabel bebas yang dijadikan input dalam formula adalah jumlah unit dari UPI per masing-masing kelompok (mikro, kecil, dan menengah/UMKM) sebagai berikut (Ditjen PDS-KKP 2015):

$\mathrm{BB}=\mathrm{BBH} \times \mathrm{f} \times \mathrm{UPI}$

Keterangan:

$\mathrm{BB}=$ Kebutuhan bahan baku per tahun $(\mathrm{kg})$

$\mathrm{BBH}=$ kebutuhan bahan baku harian $(\mathrm{kg})$

$\mathrm{f}=$ frekuensi produksi per tahun (terkait musim)

UPI $=$ jumlah unit dari UPI per pengelompokan

Beberapa asumsi yang perlu ditetapkan dalam penelitian ini adalah bahwa proses

Table 1 Amount of raw material in MSMEs processing unit in each category stock capability of each WPP

\begin{tabular}{|c|c|c|c|c|}
\hline \multirow{2}{*}{ MSMEs Product } & \multicolumn{4}{|c|}{$\begin{array}{c}\text { Amount of raw material }(\mathrm{kg}) \text { each } \\
\text { group }\end{array}$} \\
\hline & Micro & Small & Medium & Total $^{*}$ \\
\hline Pindang & 167 & 833 & 1,250 & 2,250 \\
\hline Salted fish & 160 & 800 & 1,200 & 2,160 \\
\hline Smoked fish & 153 & 763 & 1,145 & 2,061 \\
\hline Others $^{* *}$ & 287 & 666 & 1,000 & 1,953 \\
\hline
\end{tabular}


Table 2 Capacity, utility (\%), and efficiency of fish processing industrial and MSMEs

\begin{tabular}{ccrrrrr}
\hline Comodities & $\begin{array}{c}\text { Type of } \\
\text { Processing }\end{array}$ & $\begin{array}{c}\text { Maximum } \\
\text { capacity (ton/ } \\
\text { day/unit) }\end{array}$ & $\begin{array}{c}\text { Effective } \\
\text { capacity (ton/ } \\
\text { day/unit) }\end{array}$ & $\begin{array}{c}\text { Average } \\
\text { Production } \\
\text { (ton/day/unit) }\end{array}$ & $\begin{array}{c}\text { Utility } \\
(\%)\end{array}$ & $\begin{array}{c}\text { Efficiency } \\
(\%)\end{array}$ \\
\hline Tuna (TTC) & Fresh & 12.20 & 7.70 & 5.00 & 48.67 & 67.05 \\
Tuna (TTC) & Frozen & 47.60 & 16.20 & 4.10 & 48.81 & 71.33 \\
Tuna (TTC) & Canning & 24.00 & 20.00 & 18.00 & 75.00 & 90.00 \\
Shrimp & Frozen & 39.58 & 23.16 & 22.41 & 54.43 & 104.44 \\
Others & Fresh & 20.23 & 16.87 & 13.50 & 68.25 & 81.11 \\
Others & Frozen & 37.67 & 20.75 & 14.83 & 52.51 & 69.92 \\
Others & Canning & 21.42 & 18.33 & 14.43 & 58.61 & 76.21 \\
Others & Canning & 4.75 & 3.00 & 1.75 & 50.83 & 62.50 \\
\multicolumn{2}{c}{ Average } & 25.93 & 15.75 & 11.75 & 57.14 & 77.82 \\
\multicolumn{2}{c}{\begin{tabular}{c} 
Deviation \\
\multicolumn{2}{l}{ Coefisien variation }
\end{tabular}} & 14.58 & 6.90 & 7.33 & 9.67 & 13.76 \\
\hline
\end{tabular}

Note: ${ }^{*}$ used to calculate of raw material for industry as effective capacity use for production.

penentuan bahan baku sudah mengikuti pola harian dalam setahun dengan adanya pengaruh fluktuasi suplai bahan baku. Jumlah hari produktif pertahun (frekuensi) adalah 287 hari (memperhitungkan jumlah hari tidak produksi saat musim barat dari komunikasi dengan pengolah). Total produksi per hari dari setiap UMKM adalah total produksi maksimum setiap kali produksi (kg) per hari.

Unit pengolahan dikelompokkan dalam empat kelompok utama yaitu pindang, asin, asap dan sisanya digabung dalam kelompok olahan lainya. Jumlah kebutuhan bahan baku berasal dari kumulatif ketiga kelompok tersebut seperti terlihat pada Table 1.

Berdasarkan hasil perhitungan hari operasi dari semua UMKM dengan memperhatikan libur, hari minggu, maka diperoleh rata-rata hari aktif di semua UMKM sebanyak 287 hari per tahun. Perhitungan total kebutuhan alokasi kemampuan daya dukung industri dari total bahan baku dapat dihitung.

Berdasarkan data statistik 2016 terdapat tiga kelompok industri yaitu TTC, udang, dan lainnya. Tuna terdiri atas tuna segar, tuna beku, dan tuna kaleng. Udang terdiri atas udang beku sedangkan kelompok lainnya terdiri atas industri ikan segar, beku, kaleng, dan kering. Berdasarkan 612 data industri yang dianalisis, diketahui kapasitas terpasang, kapasitas efektif, produk olahan, tingkat utilitas, dan efisiensi sebagaimana disajikan pada Table 2

Data Table 2, maka ditetapkan nilai kapasitas efektif dari industri pengolahan sebagai jumlah bahan baku yang selalu digunakan dalam setiap proses pengolahan. Untuk penentuan jumlah daya dukung industri dari stok yang tersedia, maka nilai kapasitas efektif dijadikan sebagai ukuran kebutuhan tiap unit dalam setiap proses pengolahan. Berdasarkan data yang sama diketahui juga hari efektif rata-rata usaha pengolahan dalam setahun adalah 312 hari. Analisis bahan baku ditentukan dari nilai kapasitas efektif operasional industri. Potensi stok pada MSY disetiap WPP didistribusikan pada unit usaha UMKM dan industri.

Rasio kebutuhan antara industri dan pengolahan UMKM ditentukan berdasarkan kebutuhan total bahan baku yang telah dihitung. Berdasarkan analisis data 2014 dan 2015 maka kebutuhan bahan baku untuk UMKM mencapai 3,29 juta ton, dan industri besar 1,76 juta ton. Dengan demikian persentase kebutuhan setiap kelompok industri, dapat ditentukan seperti pada Table 3.

\section{Alokasi Stok Bahan Baku}

Alokasi proporsional dari total potensi jumlah tangkap boleh (JTB/MSY) pada 
Table 3 Ratio of raw material stock in each Industry and MSMEs

\begin{tabular}{|c|c|c|c|}
\hline Comodities & Raw material & $\begin{array}{l}\text { Distribution } \\
\text { for }\end{array}$ & $\begin{array}{c}\text { Effective } \\
\text { capacity (ton/ } \\
\text { day/unit) }\end{array}$ \\
\hline \multirow[t]{4}{*}{ MSMEs } & \multirow{4}{*}{$\begin{array}{l}3.29 \text { million ton/year } \\
(65.15 \%)\end{array}$} & Pindang & $15.32 \%$ \\
\hline & & Salted fish & $43.68 \%$ \\
\hline & & Smoked fish & $16,94 \%$ \\
\hline & & Others & $24.06 \%$ \\
\hline \multirow[t]{4}{*}{ Industry } & \multirow{4}{*}{$\begin{array}{l}1.76 \text { million ton/year } \\
(34.85 \%)\end{array}$} & Tuna (TTC) & $25.51 \%$ \\
\hline & & Shrimp & $25.32 \%$ \\
\hline & & Fresh and Canning & $18.38 \%$ \\
\hline & & Other fish & $30.79 \%$ \\
\hline Raw Material Total & 5.05 million ton/year & 0.56 & 0.44 \\
\hline
\end{tabular}

Note: Raw material and percentage getting from evaluation of MSMEs raw material monitoring in 2010-2015 and Industry in 2016;. Percentage use for stock allocation of raw material in each processing group

seluruh wilayah perairan Indonesia dilakukan untuk menentukan daya dukung industri dan UMKM di setiap WPP. Alokasi proporsional digunakan karena prinsip pengalokasian total contoh ke masing-masing lapisan secara proporsional yang diasumsikan seimbang dari total populasi pada lapisan ke-i terhadap total populasi di setiap wilayah pengelolaan perikanan (Krebs 1998).

$\mathrm{ni}=\mathrm{nx} \frac{\mathrm{Ni}}{\mathrm{N}}$

Keterangan:

ni = alokasi bahan baku pada wpp ke-1 (ton/wpp)

$\mathrm{n}=$ total dari jumlah tangkap boleh (JTB) pada setiap wpp ke-I (ton)

$\mathrm{Ni}=$ total kebutuhan bahan baku (industri dan dan UMKM) (ton)

$\mathrm{N}$ = total jumlah tangkap boleh total dari semua WPP NRI (ton)

\section{HASIL DAN PEMBAHASAN Wilayah Pengelolaan Perikanan}

Menurut UU No 45 tahun 2014 tentang perikanan, bahwa pembangunan perikanan menurut wilayah pengelolaan perikanan mencakup kegiatan penangkapan, budi daya (mariculture), dan konservasi. Hasil tangkapan kemudian akan dimanfaatkan sebagai bahan baku industri perikanan dan UMKM. Wilayah pengelolaan perikanan sebagai ruang ekonomi dapat dimanfaatkan agar usaha perikanan lebih terkontrol dan tidak mudah habis (Wiadnya et al.
2017). Komitmen pemerintah menerapkan mekanisme pemanfaatan perikanan berbasis WPP juga ditegaskan dalam Perpres No 18 tahun 2020 tentang RPJM 2020-2024. Komitmen ini merupakan penegasan bahwa satuan ruang pembangunan perikanan harus berbasis WPP. Untuk itu skema industri perikanan juga mulai dirancang berbasis bahan baku di setiap WPP sehingga lebih fokus dan terarah.

Berdasarkan keputusan menteri Kelautan dan Perikanan atas WPPNRI, dugaan total potensi stok ikan di wilayah RI mencapai 12,541 juta ton per tahun lebih tinggi dari estimasi potensi tahun 2014 (Suman et al. 2017). Potensi stok pada MSY/(JTB) jumlah tangkap boleh sebesar $80 \%$ dari total stok yaitu 10,03 juta ton yang dapat dimanfaatkan (Ma’mun et al. 2017). Potensi tangkapan agar stok lestari adalah 10,03 juta ton/tahun di seluruh WPP N RI belum termasuk perikanan di laut bebas (Fauzi 2005). Sebaran dari JTB dari total stok tiap WPP kemudian dialokasikan secara proporsional pada Figure 2.

Berdasarkan gambar tersebut, terlihat bahwa WPP 718 merupakan daerah dengan potensi stok dan tingkat pemanfaatan terbesar $(21,03 \%)$ dari total potensi stok dan juga termasuk wilayah dengan produktivitas yang tinggi (Yonvitner 2007) dari daerah lainnya. Sehingga menyumbang lebih banyak pada ketersediaan bahan baku untuk industri. 


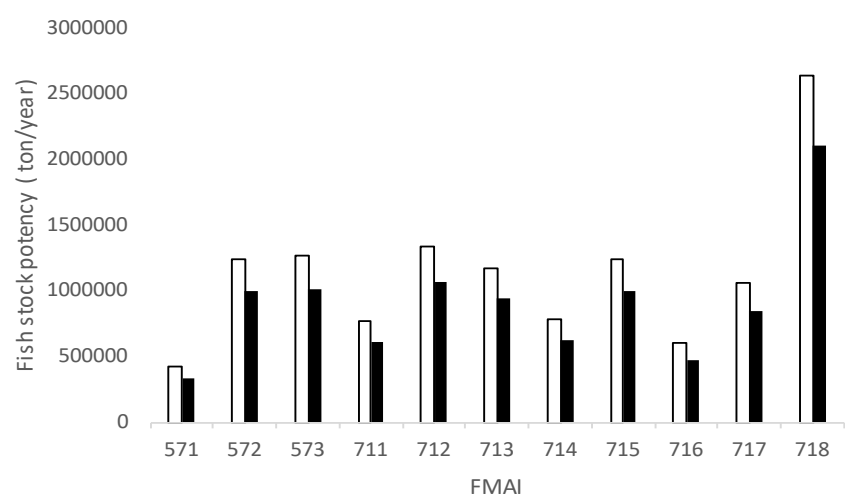

(a)

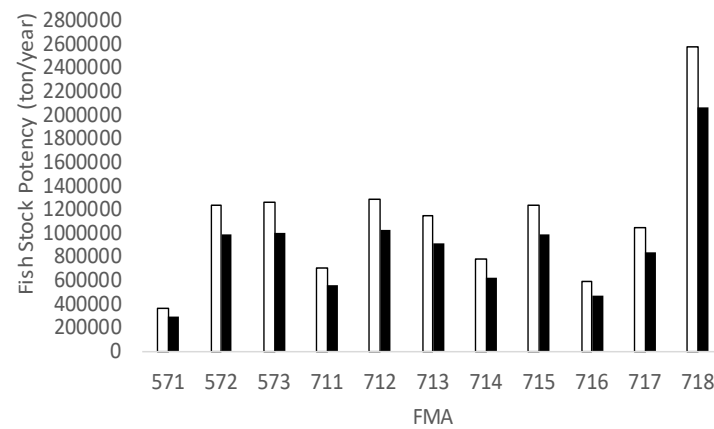

(b)

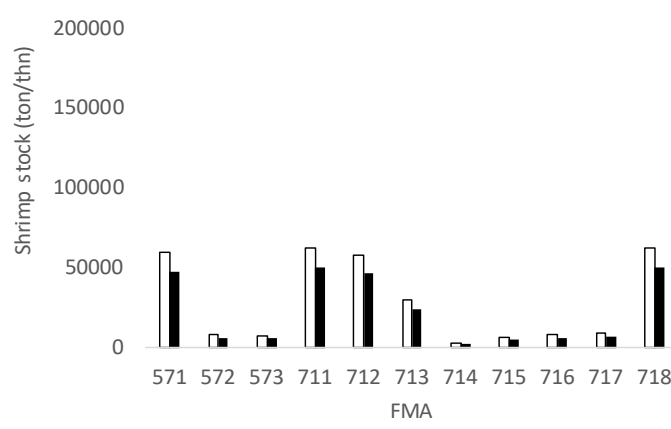

(c)

Figure 2 (a) $\square$ fish stock potency, $\mathbf{\square}$ total allowable catch (TAC) $80 \%$ of stock (b) $\square$ total fish stock (excluded shrimp), $\mathbf{a}$ TAC $80 \%$ without shrimp; (c) $\sqcup$ total of shrimp stock, $\mathbf{\square}$ TAC shrimp (MSY) $80 \%$

Sementara itu daerah penghasil udang di pesisir timur sumatra (WPP 571), Laut Natuna (711), Laut Jawa (712) dan Selat Makassar (713) serta Laut Arafuru (WPP 718) yang didominasi udang Jerbung (Hargiyatno et al. 2015) untuk mendukung bahan baku industri udang. Sementara WPP 571, 572 dan 717 serta 715 adalah daerah penghasil cakalang yang terlihat meningkat (Lubis et al. 2011) yang berpotensi untuk mendukung industri.

Pembagian kode WPP secara lengkap adalah sebagai berikut: 571 Selat Malaka dan Laut Andaman; 572 Samudra Hindia sebelah barat Sumatra dan Selat Sunda; 573 Samudra Hindia selatan Jawa hingga Laut Timor bagian Barat; 711 Selat Karimata, Laut Natuna, dan Laut China Selatan; 712 Laut Jawa; 713 Selat Makassar, Teluk Bone, Laut Flores, dan Laut Bali; 714 Teluk Tolo dan Laut Banda; 715 Teluk Tomini, Laut Maluku, hingga Teluk Berau; 716 Laut Sulawesi dan sebelah utara Pulau Halmahera; 717 Teluk Cendrawasih dan Laut Pasifik; dan 718 Laut Aru, Laut Arafuru, dan Laut Timor bagian timur.

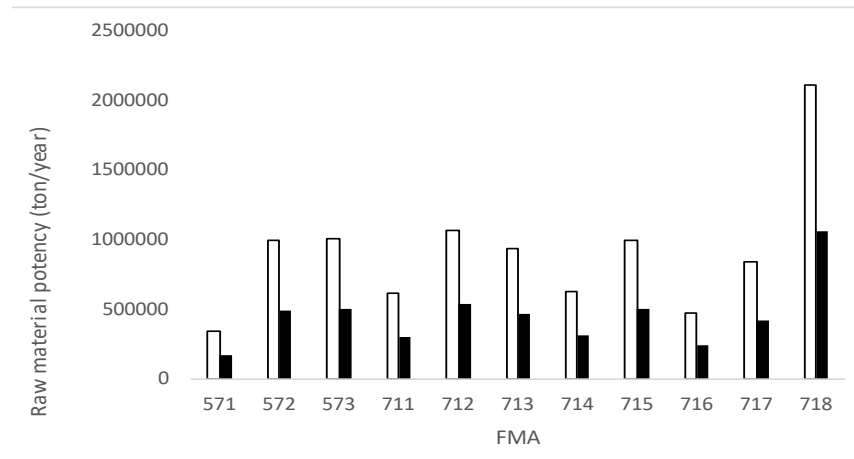

Figure 3 Quota allocation of raw material in each FMA; $\sqcup$ ) total allowable catch (TAC) $80 \%$ of stock

- raw material allocation $(5.05 / 10.03) \times \mathrm{TAC}$ 


\section{Alokasi Bahan Baku tiap WPP}

Penentuan kebutuhan bahan baku untuk Industri dan UMKM penting untuk menjaga kontinuitas industri perikanan (Sulaefi 2011). Berdasarkan data UPI untuk UMKM (20102015) dan data Industri (2015-2016), total kebutuhan bahan baku sebesar 5,051 juta ton/ tahun. Penetapan alokasi untuk kelompok usaha industri dan UMKM mengacu pada persentase pada Table 3. Dengan analisis alokasi proporsional, maka alokasi kuota bahan baku setiap WPP dapat diketahui seperti disajikan pada Figure 3

Jumlah bahan baku pada Indonesia timur tergolong tinggi (Yonvitner et al. 2020) termasuk WPP 718, sedangkan di bagian barat di antaranya WPP 571 tergolong rendah. Potensi stok yang rendah sering juga disebabkan karena stok yang dicuri atau lemahnya pengawasan seperti di 711 (Hozairi et al. 2017) yang sering terjadi pencurian. Nilai stok pada kondisi MSY sampai tahun 2016 tidak semuanya termanfaatkan untuk bahan baku. Penyerapan bahan baku rendah (tidak semua stok MSY) digunakan untuk pengolahan walaupun 38\% (Suman et al. 2018) WPP sudah tergolong over-eksploitasi.

Selama ini bahan baku dari setiap WPP dikelola berdasarkan alokasi proporsional dari setiap WPP. Di mana alokasi yang besar kuota bahan baku diambil dari potensi stok dan JTB yang juga besar. Berdasarkan analisis, diperoleh WPP 712, 715, dan 718 merupakan daerah dengan potensi alokasi bahan baku terbesar terutama ikan demersal (Mamun et al. 2018). Sedangkan WPP 572,
573, 715, dan 717 diperkirakan sebagai daerah persebaran pelagis besar. Untuk WPP 573 distribusi pelagis besar tergolong unit dan diduga dipengaruhi monsun, Arus Lintas Indonesia, dan Indonesia Ocean Dipole (IOD) (Hakim et al. 2019). Pola distribusi dan kebutuhan dari alokasi bahan baku disajikan pada Figure 4 dan Table 1.

Dari alokasi bahan baku yang ada tersebut, kebutuhan UMKM terlihat lebih besar dari bahan baku Industri. UMKM lebih banyak menyerap ikan tangkapan dibandingkan industri menengah dan besar. Kebutuhan bahan baku untuk UMKM lebih dominan untuk pindang, asap, asin, dan pengolahan lainnya. Sementara jenis ikan tuna dan cakalang sebagai bahan baku olahan industri untuk ekspor (Witomo dan Wardoyo 2012) pada industri pengolahan ikan TTC (tuna tongkol cakalang), udang, ikan segar dan kaleng serta ikan olahan lainnya.

\section{Daya Dukung Bahan Baku}

Penentuan daya dukung industri dan UMK dari jumlah tangkap lestari dilakukan setelah mengetahui tingkat kemampuan ratarata industri dan UMKM menyerap bahan baku yang dibutuhkan. Daya dukung lestari juga merupakan representasi dari proses pengelolaan perikanan berkelanjutan (Atmaja dan Nugroho 2017) antar berbagai dimensi yang ada.

\section{Hari Operasi}

Untuk industri hari operasi adalah 312 hari dalam setahun, dan UMKM 287 hari dalam setahun. Sistem kerja yang lebih ketat,

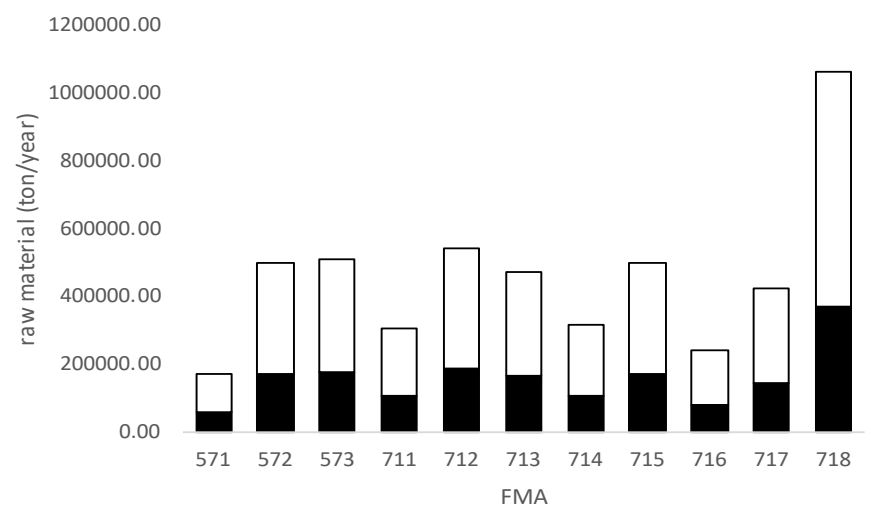

Figure 4 Raw material allocation for Industry and MSME in FMAs; $\sqcup$ | total raw material for MSME (65.15\%) - total raw material for industry (34.85\%) 
ketersediaan gudang bahan baku dan pola penggajian menyebabkan industri memiliki hari kerja lebih lama dibandingkan UMKM. Sementara karena UMKM tidak memiliki gudang,bahan baku yang ada langsung diolah, ketersediaannya juga dipengaruhi oleh musim, di mana ada masanya hasil tangkapan rendah dan ikan tidak tersedia.

\section{Daya Dukung Stok Untuk Bahan Baku}

Daya dukung bahan baku adalah jumlah stok yang tersedia dan mampu mendukung ketersediaan bahan baku industri dan UMKM. Dengan mempertimbangkan jumlah kebutuhan bahan baku harian pada usaha industri dan UMKM, maka dapat dihitung jumlah industri yang bisa didukung keberlanjutannya oleh stok yang tersedia secara berkelanjutan. Dalam hal penentuan daya dukung disusun dalam 3 skenario yang dibuat dengan beberapa asumsi; pertama, jumlah bahan baku rata-rata yang digunakan sebagai hasil dari perhitungan tahunan dapat digunakan sebagai prakiraan bahan baku dalam satu tahun; kedua, jumlah hari operasi UMKM dan industri yang diperoleh sebagai rata-rata dalam setahun dianggap mewakili adanya perbedaan hari operasi. Skenario ketiga perhitungan daya dukung bahan baku pada kondisi MSY total sebagai berikut.

Skenario 1: Semua potensi ikan pada tingkat MSY ( $80 \%$ dari total stok) dialokasikan semuanya (100\%) sebagai bahan baku Industri (tidak termasuk UMKM). Skenario ini diperlukan untuk melihat kemungkinan jika kebijakan industrialisasi dianggap baik. Skenario 1 terdapat pada Table 4. Dengan tingkat kapasitas efektif terpasang dari TTC, udang dan lainnya, maka daya dukung stok mencapai 340 unit yang terdiri dari 130 unit TTC, 35 unit udang, dan 175 unit industri lainnya. Berdasarkan sediaan stok, daya dukung WPP 718 adalah yang paling besar. Ruliza (2019) menyatakan bahwa aktivitas pengolahan ikan di Banda Aceh sebagian besar bahan bakunya adalah tuna, tongkol dan ikan kambing-kambing.

Skenario 2: semua potensi ikan pada tingkat MSY ( $80 \%$ dari total stok) dialokasikan sebesar $34,85 \%$ untuk industri termasuk udang. Perhitungan skenario 2 pada Table 4 memperlihatkan bahwa bahan baku industri pada tingkat MSY dipisah dengan komposisi $34,85 \%$. Total total daya dukung untuk industri hanya 80 unit dengan komposisi 45 unit industri berbasis ikan, dan 35 unit industri dari udang. Secara spasial, bahwa potensi ikan pada WPP 718 masih sangat besar.

Skenario 3: semua potensi ikan pada tingkat MSY (80\% dari total stok) alokasi sebesar 65,15\% dari stok untuk usaha UMKM. Perhitungan skenario 3 menunjukkan bahwa alokasi stok untuk UMKM 65,15\% mampu mendukung sebanyak 3.032 unit usaha. Jumlah ini terdiri dari 810 unit pindang, 778 unit asing, 741 unit asap, dan 702 unit jenis olahan lainnya. Secara umum daya dukung stok WPP 718 bahan bakunya tetap lebih besar dibandingkan WPP lainnya. Keseluruhan WPP untuk industri dan UMKM daya dukung bahan baku untuk industri mencapai 3.112 unit. Skenario pengelolaan menurut WPP seperti sebuah klaster diperlukan untuk memastikan usaha pengolahan lebih efektif termasuk nilai tambah (Ayu et al. 2013).

Dari total potensi lestari (MSY) jumlah total industri yang dapat didukung dari stok tersebut adalah 3111 unit yang terdiri dari 80 unit industri dengan total rata-rata kebutuhan perhari 102,85 ton dan udang beku 35 unit. Sebanyak 3031 unit pengolahan UMKM (pindang, asing, asap dan lainnya) dengan kebutuhan mencapai 8,42 ton per hari.

Dalam perspektif pembangunan perikanan, bahwa keberadaan industri dan UMKM penting untuk mendukung ekonomi dan penciptaan lapangan pekerjaan. Berdasarkan survei (2014-2016) bahwa rata-rata kebutuhan tenaga kerja industri sebanyak 300 per unit dengan komposisi pendidikan dasar $10 \%$, menengah $85 \%$ dan pendidikan tinggi 5\%. Dengan jumlah 80 industri, maka terdapat sebanyak potensial 24.000 tenaga kerja. Sementara itu pada UMKM dengan 3032 unit, dengan rata-rata tenaga kerja sebanyak (lebih kurang 20 orang per unit), maka ada sekitar 60.640 orang tenaga kerja dari semua WPP yang ada. Dari segi perbandingan tersebut, usaha UMKM lebih kompetitif dibandingkan industri (Anggraeni et al. 2017) untuk penciptaan 
Table 4 Total stock capacity for industry (scenario 1 total stock, and scenario 2 as $34.5 \%$ of total stock based proportional allocation)

\begin{tabular}{|c|c|c|c|c|c|c|c|c|c|c|}
\hline \multicolumn{11}{|c|}{ Scenario 1 (Total MSY allocate for large industry) } \\
\hline Industry & TTC & TTC & TTC & Shrimp & Others & Others & Others & Others & $\begin{array}{c}\text { Total } \\
\text { without } \\
\text { shrimps }\end{array}$ & $\begin{array}{c}\text { Total } \\
\text { with } \\
\text { shrimps }\end{array}$ \\
\hline Product & Fresh & Frozen & Canning & Frozen & Fresh & Frozen & Canning & Canning & & \\
\hline ton & 7.70 & 16.20 & 20.00 & 23.16 & 16.87 & 20.75 & 18.33 & 3.00 & 102.85 & 126.01 \\
\hline 571 & 0.68 & 1.44 & 1.77 & 6.58 & 1.50 & 1.84 & 1.63 & 0.27 & 9.12 & 15.71 \\
\hline 572 & 2.30 & 4.84 & 5.98 & 0.89 & 5.04 & 6.20 & 5.48 & 0.90 & 30.74 & 31.63 \\
\hline 573 & 2.35 & 4.95 & 6.11 & 0.81 & 5.15 & 6.34 & 5.60 & 0.92 & 31.42 & 32.23 \\
\hline 711 & 1.32 & 2.77 & 3.42 & 6.90 & 2.88 & 3.54 & 3.13 & 0.51 & 17.57 & 24.47 \\
\hline 712 & 2.40 & 5.04 & 6.22 & 6.42 & 5.25 & 6.46 & 5.70 & 0.93 & 32.00 & 38.42 \\
\hline 713 & 2.14 & 4.51 & 5.56 & 3.37 & 4.69 & 5.77 & 5.10 & 0.83 & 28.61 & 31.97 \\
\hline 714 & 1.47 & 3.09 & 3.81 & 0.35 & 3.21 & 3.95 & 3.49 & 0.57 & 19.59 & 19.94 \\
\hline 715 & 2.31 & 4.85 & 5.99 & 0.71 & 5.05 & 6.22 & 5.49 & 0.90 & 30.82 & 31.53 \\
\hline 716 & 1.10 & 2.31 & 2.86 & 0.88 & 2.41 & 2.96 & 2.62 & 0.43 & 14.69 & 15.57 \\
\hline 717 & 1.95 & 4.11 & 5.07 & 1.01 & 4.28 & 5.26 & 4.65 & 0.76 & 26.07 & 27.08 \\
\hline 718 & 4.81 & 10.11 & 12.48 & 6.96 & 10.53 & 12.95 & 11.44 & 1.87 & 64.19 & 71.15 \\
\hline Total & 22.82 & 48.01 & 59.27 & 34.88 & 50.00 & 61.50 & 54.32 & 8.89 & 304.81 & 339.69 \\
\hline \multicolumn{11}{|c|}{ Scenario 2 (Total raw material quota for industry $34.85 \%$ from MSY) } \\
\hline Product & Fresh & Frozen & Canning & Frozen & Fresh & Frozen & Canning & Canning & & \\
\hline ton & 7.70 & 16.20 & 20.00 & 23.16 & 16.87 & 20.75 & 18.33 & 3.00 & 102.85 & 126.01 \\
\hline 571 & 0.01 & 0.02 & 0.03 & 6.58 & 0.02 & 0.03 & 0.02 & 0.00 & 0.13 & 6.71 \\
\hline 572 & 0.39 & 0.82 & 1.02 & 0.89 & 0.86 & 1.05 & 0.93 & 0.15 & 5.23 & 6.12 \\
\hline 573 & 0.40 & 0.84 & 1.04 & 0.81 & 0.88 & 1.08 & 0.96 & 0.16 & 5.36 & 6.17 \\
\hline 711 & 0.13 & 0.28 & 0.35 & 6.90 & 0.30 & 0.36 & 0.32 & 0.05 & 1.80 & 8.70 \\
\hline 712 & 0.33 & 0.70 & 0.86 & 6.42 & 0.73 & 0.89 & 0.79 & 0.13 & 4.42 & 10.84 \\
\hline 713 & 0.33 & 0.69 & 0.85 & 3.37 & 0.72 & 0.89 & 0.78 & 0.13 & 4.39 & 7.76 \\
\hline 714 & 0.25 & 0.53 & 0.66 & 0.35 & 0.55 & 0.68 & 0.60 & 0.10 & 3.37 & 3.72 \\
\hline 715 & 0.39 & 0.83 & 1.03 & 0.71 & 0.87 & 1.06 & 0.94 & 0.15 & 5.27 & 5.99 \\
\hline 716 & 0.18 & 0.38 & 0.47 & 0.88 & 0.40 & 0.49 & 0.43 & 0.07 & 2.41 & 3.29 \\
\hline 717 & 0.33 & 0.69 & 0.85 & 1.01 & 0.72 & 0.88 & 0.78 & 0.13 & 4.39 & 5.40 \\
\hline 718 & 0.75 & 1.57 & 1.94 & 6.96 & 1.64 & 2.01 & 1.78 & 0.29 & 9.97 & 16.93 \\
\hline Total & 3.35 & 7.05 & 8.71 & 34.88 & 7.34 & 9.03 & 7.98 & 1.31 & 44.78 & 79.66 \\
\hline
\end{tabular}

lapanan kerja

Daya dukung yang rendah di WPP 571 dan 714 serta yang tinggi di 718 dalam kegiatan ekosistem tetap perlu dipantau agar tetap besar dampaknya terdahap peningkatan kekayaan stok ikan. Untuk itu pemilihan bahan baku unggulan setiap WPP penting menetapkan jenis industri yang akan dibangun (Hamzah et al. 2015). Secara umum jika dibandingkan dengan fakta dan data yang dihitung, bahwa industri UMKM mencapai 3.112 unit lebih rendah dari fakta jumlah industri saat ini yaitu lebih 63.005 unit dan UMKM 650 unit. Dengan data seperti ini terlihat bahwa jumlah stok masing sangat rendah pemanfaatannya, akibatnya bahan baku sering diimpor. Namun optimalisasi pemanfaatan stok di WPP bisa dilakukan 
Table 5 Total stock capacity for industry capacity for Scenarion 3 MSME (65,15\% of total stock at MSY) and total of carrying capacity of stock at MSY

\begin{tabular}{|c|c|c|c|c|c|c|c|}
\hline \multicolumn{8}{|c|}{ Scenario 3 (Total raw material quota for MSME $65.16 \%$ from MSY) } \\
\hline Product & Pindang & Asin & Asap & Others & Total & & \\
\hline ton & 2.25 & 2.16 & 2.06 & 1.95 & 8.42 & & \\
\hline 571 & 24.25 & 23.28 & 22.21 & 21.02 & 90.76 & & \\
\hline 572 & 81.71 & 78.44 & 74.81 & 70.81 & 305.77 & & \\
\hline 573 & 83.51 & 80.17 & 76.46 & 72.38 & 312.53 & & \\
\hline 711 & 46.71 & 44.84 & 42.76 & 40.48 & 174.78 & & \\
\hline 712 & 85.07 & 81.67 & 77.89 & 73.73 & 318.35 & & \\
\hline 713 & 76.04 & 73.00 & 69.62 & 65.90 & 284.57 & & \\
\hline 714 & 52.07 & 49.99 & 47.68 & 45.13 & 194.87 & & \\
\hline 715 & 81.92 & 78.64 & 75.00 & 70.99 & 306.55 & & \\
\hline 716 & 39.05 & 37.48 & 35.75 & 33.84 & 146.12 & & \\
\hline 717 & 69.29 & 66.52 & 63.44 & 60.05 & 259.29 & & \\
\hline 718 & 170.63 & 163.80 & 156.22 & 147.88 & 638.53 & & \\
\hline \multicolumn{8}{|c|}{ Carrying capacity } \\
\hline & $\begin{array}{c}\text { Stock } \\
\text { potency at } \\
\text { MSY }\end{array}$ & $\begin{array}{c}\text { Stock } \\
\text { potency for } \\
\text { industry }\end{array}$ & $\begin{array}{c}\text { Stock } \\
\text { potency for } \\
\text { MSME }\end{array}$ & $\begin{array}{c}\text { Stock } \\
\text { potency } \\
\text { with shrimp }\end{array}$ & $\begin{array}{c}\text { Total } \\
\text { Capacity } \\
\text { Stock for } \\
\text { Industry }\end{array}$ & $\begin{array}{c}\text { Total } \\
\text { Capacity } \\
\text { Stock for } \\
\text { MSME }\end{array}$ & $\begin{array}{c}\text { Total } \\
\text { Capacity } \\
\text { Stock for } \\
\text { Industry and } \\
\text { MSME }\end{array}$ \\
\hline 571 & $340,355.2$ & $118,613.2$ & $221,741.4$ & $71,049.8$ & 6.71 & 90.76 & 97.48 \\
\hline 572 & 992,780 & $345,983.8$ & $646,796.2$ & $339,565.4$ & 6.12 & 305.77 & 311.89 \\
\hline 573 & $1,014,032$ & $353,390.2$ & $660,641.8$ & $347,518.2$ & 6.17 & 312.53 & 318.70 \\
\hline 711 & $613,700.8$ & 213.874 .7 & $399,826.1$ & $164,001.1$ & 8.70 & 174.78 & 183.49 \\
\hline 712 & $1,073,305.6$ & $374,047.0$ & $699,258.6$ & $327,675.0$ & 10.84 & 318.35 & 329.19 \\
\hline 713 & $942,285.6$ & $328,386.5$ & $613,899.1$ & $304,063.3$ & 7.76 & 284.57 & 292.33 \\
\hline 714 & $631,151.2$ & $219,956.2$ & $411,195.0$ & $217,412.2$ & 3.71 & 194.87 & 198.59 \\
\hline 715 & $994,020.8$ & $346,416.2$ & $647,604.6$ & $341,267.4$ & 5.99 & 306.55 & 312.54 \\
\hline 716 & $477,711.2$ & $166,482.4$ & $311,228.8$ & $160,126.4$ & 3.29 & 146.12 & 149.41 \\
\hline 717 & $843,756.0$ & $294,049.0$ & $549,707.0$ & $286,729.0$ & 5.40 & 259.29 & 264.69 \\
\hline 718 & $2,110,052$ & $735,353.1$ & $1,374,698.9$ & $685,079.5$ & 16.93 & 638.53 & 655.45 \\
\hline Total & $10,033,150.4$ & $3,496,552.9$ & $6,536,597.5$ & $3,244,487.3$ & 79.66 & $3,032.11$ & $3,111.77$ \\
\hline
\end{tabular}

dengan memperkuat teknologi WebGIS untuk memastikan daerah penangkapan (Suhelmi and Purbani 2013). Namun satu hal yang harus diingatkan bahwa ketersediaan stok ikan air tawar perlu dipercepat serta jika tidak mau rugi dilakukan rasionalisasi usaha perikanan.

Praktikperizinanyangtidakmemerhatikan daya dukung stok dikhawatirkan akan terus menguras sumber daya atau menuntut adanya impor. Untuk itu perlu segera dipetakan secara tepat bahan baku stok pada MSY di setiap WPP, serta jumlah kapal yang beroperasi.

\section{KESIMPULAN}

Daya dukung stok ikan laut pada MSY untuk usaha industri pengolahan dan UMKM mencapai 3.111 unit, yang lebih rendah dari jumlah UMKM dan industri yang ada saat ini. 
Jumlah UMKM dan industri yang diperoleh ini adalah jumlah unit pengolahan ikan yang mampu berproduksi secara berkelanjutan selama 12 bulan. Jumlah UPI tersebut mampu menciptakan lapangan pekerjaan mencapai 84.640 orang. Jika kita ingin meningkatkan jumlah tenaga kerja, maka perlu pengembangan dan peningkatan sumber bahan baku atau diversifikasi produk olahan dari industri yang dibangun. Selain itu juga bisa mengintegrasikan produksi ikan air tawar sebagai penguat bahan baku dan penambah tenaga kerja. Potensi stok pada MSY termasuk kurang mencukupi untuk industri pengolahan dan UMKM. Berdasarkan kebutuhan saat ini, kemampuan daya dukungnya stok pada WPP saat MSY hanya sebesar 5\% dari total UKM dan industri yang ada saat ini. Rekayasa dalam menciptakan keseimbangan ketersediaan bahan baku dengan jumlah unit industri perlu dilakukan. Strateginya dapat dilakukan melalui rasionalisasi jumlah industri perikanan, atau dengan meningkatkan bahan baku dari ikan air tawar serta memperkuat budidaya laut dan air payau.

\section{DAFTAR PUSTAKA}

Amin MZ, Nugroho LPE, Nurjanah. 2018. Kajian implementasi GMP dan SSOP ikan teri nasi setengah kering di Kabupaten Tuban. Jurnal Pengolahan Hasil Perikanan Indonesia. 21(3): 406-413

Anggraeni D, Nurjanah, Asmara DA, Hidayat T. 2019. Kelayakan industri pengolahan ikan dan mutu produk UMKM pindang tongkol di Kabupaten Banyuwangi. Jurnal Pengolahan Hasil Perikanan Indonesia. 22(1): 14-23.

Anggraeni SK, Maarif MS, Sukardi S, Raharja S. 2017. Strategi Peningkatan Daya Saing Usaha Kecil Menengah Berbasis Olahan Ikan Di Indonesia: Suatu Tinjauan. Journal Industrial Services, 3(1c).

Atmaja SB, Nugroho D. 2017. Upaya-upaya pengelolaan sumber daya ikan yang berkelanjutan di Indonesia. Jurnal Kebijakan Perikanan Indonesia. 3(2): 101113.

Ayu BW, Ismono RH, Soelaiman A. 2013. Analisis Nilai Tambah Pada Klaster
Industri Pengolahan Ikan Teri Kering Di Pulau Pasaran Kota Bandar Lampung. Jurnal Ilmu-Ilmu Agribisnis. 1(3): 246253.

Barclay K. 2012. The Social in Assessing for Sustainability. Fisheries in Australia. Cosmopolitan Civil Societies: An Interdisciplinary Journal. 4(3): 38-53.

Fauzi A. 2005. Kebijakan perikanan dan kelautan: isu, sintesis, dan gagasan. Jakarta (ID): Gramedia Pustaka Utama.

Hargiyatno IT, Anggawangsa RF, Sumiono B. 2015. Sebaran Spasio-Temporal Ukuran dan Densitas Udang Jerbung (Penaeus merguiensis de Man, 1907) di Sub Area Dolak, Laut Arafura (WPP-NRI 718). Jurnal Penelitian Perikanan Indonesia 21(4): 261-269.

Hakim L, Jatmiko I. 2019. Pemetaan kesesuaian habitat tuna sirip kuning (Thunnus albacares) menggunakan generalized additive model (GAM) pada WPP-NRI 573. [disertasi]. Yogyakarta (ID): Universitas Gadjah Mada.

Hamzah A, Pane AB, Lubis E, Solihin I. 2015. Potensi Ikan Unggulan Sebagai Bahan Baku Industri Pengolahan di PPN Karangantu (Superior fish potential as Raw Materials of Processing Industry in Karangantu Archipelagic Fishing Port). Marine Fisheries: Journal of Marine Fisheries Technology and Management. 6(1): 45-58.

Hozairi, Yaser Krisnafi, Heru Lumaksono. Sistem Pendukung Keputusan Penentuan Prioritas Wilayah Pengawasan Perikanan di WPP-711 Menggunakan Metode AHPTOPSIS.

[KKP] Kementerian Kelautan dan Perikanan. 2015. Laporan Perhitungan Kebutuhan Bahan Baku dan Volume Produk Olahan hasil Perikanan Skala UMKM 2015. Ditjen PDS-KKP RI.

[KKP] Kementerian Kelautan dan Perikanan. 2015. Formulasi Perhitungan Kebutuhan Bahan Baku dan Perhitungan Volume Produk Olahan Hasil Perikanan. Ditjen PDS KKP Jakarta.

[KKP] Kementerian Kelautan dan Perikanan. 2017. Peraturan Menteri Kelautan dan 
Perikanan No 50 Tahun 2017 tentang Estimasi Potensi, Jumlah Tangkapan yang Diperoleh, dan Tingkat Pemanfaatan Sumber Daya Ikan di Wilayah Pengelolaan Perikanan Negara Republik Indonesia.

[KKP] Kementerian Kelautan dan Perikanan. 2018. Refleksi 2018 dan Outlook 2019 Perikanan dan Kelautan. Paparan Menteri Perikanan dan Kelautan pada laporan tahunan 2018 dan outlook 2019. Jakarta

Krebs CJ. 1989. Ecological methodology (No. QH541. 15. S72. K74 1999.). New York: Harper \& Row.

Krisnafi Y, Iskandar BH, Wisudo SH, Haluan J. 2017. Penentuan Prioritas Wilayah Kerja Untuk Peningkatan Pengawasan Perikanan DI WPP NRI 711 (Priority Determination of Working Area For Surveillance Improvement in Indonesia Fisheries Management Area 711 (WPP NRI 711)). Marine Fisheries: Journal of Marine Fisheries Technology and Management, 8(2), 211-221.

Lubis E, Sumiati S. 2011. Pengembangan Industri Pengolahan Ikan ditinjau dari Produksi Hasil Tangkapan di Ppn Palabuhanratu. Marine Fisheries: Journal of Marine Fisheries Technology and Management. 2(1): 39-49.

Martell S, Froese R. 2013. A simple method for estimating MSY from catch and resilience. Fish and Fisheries. 14(4): 504-514.

Ma'mun A, Priatna A, Hidayat T, Nurulludin N. 2017. Distribusi dan Potensi Sumber daya Ikan Pelagis di Wilayah Pengelolaan Perikanan Negara Republik Indonesia 573 (WPP NRI 573) Samudera Hindia. Jurnal Penelitian Perikanan Indonesia. 23(1): 47-56.

Mamun A, Priatna A, Natsir M. 2018. Potensi dan Distribusi Spasial Ikan Demersal di Laut Jawa (WPP NRI-712) dengan Menggunakan Teknologi Hidroakustik. Jurnal Ilmu dan Teknologi Kelautan Tropis. 10(2): 489-499.

Pauly D, Christensen V, Guénette S. 2002. Towards sustainability in world fisheries. Nature. 418: 689-695.
Perpres No 18 Tahun 2020 tentang Rencana Pembangunan Jangka Menengah 20202024. Sekretariat Negara RI

Ruliza I, Affan JM, Juanda R. 2019. Studi Kebutuhan Bahan Baku Industri Pengolahan Ikan (Skala Mikro) di Kota Banda Aceh. Jurnal Ilmiah Mahasiswa Kelautan dan Perikanan Unsyiah. 3(4): 229-235.

Suman A, Irianto HE, Satria F, Amri K. 2017. Potensi dan tingkat pemanfaatan sumber daya ikan di wilayah pengelolaan perikanan Negara Republik Indonesia (WPP NRI) Tahun 2015 serta Opsi Pengelolaannya. Jurnal Kebijakan Perikanan Indonesia. 8(2): 97-100.

Suman A, Satria F, Nugraha B, Priatna A, Amri K, Mahiswara M. 2018. Status Stok Sumber Daya Ikan Tahun 2016 di Wilayah Pengelolaan Perikanan Negara Repulik Indonesia (WPP NRI) dan Alternatif Pengelolaanya. Jurnal Kebijakan Perikanan Indonesia. 10(2), 107-128.

Suhelmi IR, Purbani D. 2013. Pengelolaan sumberdaya kelautan dan perikanan berbasis wilayah pengelolaan perikanan (WPP) dengan memanfaatan WebGIS. DEPIK Jurnal Ilmu-Ilmu Perairan, Pesisir dan Perikanan. 2(2).

Sulaefi S. 2011. Kinerja Bisnis Agroindustri Pengolahan Ikan di Jawa Timur. Jurnal Bisnis: Teori dan Implementasi. 2(1): 7387.

UU No 45 Tahun 2009 tentang Perikanan. Sekretariat Negara RI.

Wiadnya DGR, Djohani R, Erdmann MV, Halim A, Knight M, Mous PJ, Soede LP. 2017. Kajian Kebijakan Pengelolaan Perikanan Tangkap di Indonesia: Menuju Pembentukan Kawasan Perlindungan Laut. Jurnal Penelitian Perikanan Indonesia. 11(3), 65-77.

Witomo CM, Wardono B. 2012. Potret perikanan tangkap tuna, cakalang dan layang di Kota Bitung. Buletin Ilmiah Marina Sosial Ekonomi Kelautan dan Perikanan. 7(1): 7-13.

Yonvitner, Boer M, Riyanto M, Kurnia R, 
Setyobudiandi I, Santoso J, Sukri N, Aziz KA. 2020. Estimasi stok suplai kebutuhan bahan baku untuk industri pengolahan ikan. Jurnal Pengolahan Hasil Perikanan Indonesia. 23(1): 158-165.

Yonvitner Y. 2007. Produktivitas nelayan, kapal dan alat tangkap di Wilayah Pengelolaan
Perikanan Indonesia. Jurnal Perikanan Universitas Gadjah Mada. 9(2): 254-266.

Yonvitner Y. 2014. Bahan baku: urat nadi industri pengolahan perikanan mikro kecil dan menengah. Risalah Kebijakan Pertanian and Lingkungan: Rumusan Kajian Strategis Bidang Pertanian dan Lingkungan. 1(3): 187-191. 